\title{
Post-operative outcomes of endoscopic dacrocystorhinostomy without intubation at holy family hospital, Pakistan.
}

1. MBBS, FCPS

Assistant Professor ENT

Holy Family Hospital.

2. MBBS, FCPS, FRCS

Associate Professor ENT

Benazir Bhutto Hospital.

3. MBBS, FCPS

Senior Registrar ENT

Holy Family Hospital.

4. MBBS

House Officer

Rawalpindi Medical University.

5. MBBS, FCPS

Assistant Professor ENT Benazir Bhutto Hospital.

6. MBBS, FCPS

Assistant Professor ENT

Pakistan Institute of Medical

Sciences.

Correspondence Address:

Dr. Muhammad Sheharyar Khan

Department of Surgery

Allied Rawalpindi Medical University

shehryarkhan94@hotmail.com

Article received on:

$14 / 10 / 2020$

Accepted for publication:

$24 / 12 / 2020$

\begin{abstract}
Nayyer Ayub1, Ahmed Hasan Ashfaq², Haitham Akash ${ }^{3}$, Muhammad Sheharyar Khan ${ }^{4}$, Muhammad Arshad ${ }^{5}$, Malik Jawad Faisal ${ }^{6}$

ABSTRACT... Objective: This study aims to present the outcomes of the patients who underwent endoscopic dacryocystorhinostomy (DCR) without intubation at a tertiary care hospital. Study Design: Observational Study. Setting: Holy Family Hospital, Rawalpindi, Pakistan. Period: October 2018 to November 2019. Material \& Methods: Endoscopic dacryocystorhinostomy operation was performed in a total of 52 patients presenting with chronic epiphora. Silastic tubes were not used to maintain the patency. Patients were prescribed antibiotic eye drops, oral painkillers, decongestant eye drops, and regular nasal douches. Results: Fifty patients (96.2\%) presented with successful post-operative outcomes on the 12th week for follow-up. Post-operative canal patency was evaluated by endoscopic examination and syringing. Patients were also evaluated for the presence of epiphora. Conclusion: Our results of 52 patients who underwent endoscopic DCR without stenting are as promising as those with stenting. Hence, the procedure without intubation is recommended.
\end{abstract}

Key words: Dacrocystitis, Dacryocystorhinostomy (DCR), Intubation, Nasolacrimal Duct, Pakistan.

Article Citation: Ayub N, Ashfaq AH, Akash H, Khan MS, Arshad M, Faisal MJ. Post-operative outcomes of endoscopic dacrocystorhinostomy without intubation at holy family hospital, Pakistan. Professional Med J 2021; 28(7):1008-1012. https://doi.org/10.29309/TPMJ/2021.28.07.6148

\section{INTRODUCTION}

The operative procedure of creating a lacrimal drainage pathway to enhance or facilitate the flow of the previously obstructed excreting system is termed as Dacrocystorhinostomy (DCR). ${ }^{1}$ DCR may be performed by an endoscopic approach and an external approach, both of which have their implications, indications, and post-operative success rates. ${ }^{2}$ The indications for the operation mainly include nasolacrimal duct obstruction (NLDO). NLDO may manifest in two forms, i.e primary acquired nasolacrimal duct obstruction (PANDO) and secondary acquired nasolacrimal duct obstruction (SANDO). ${ }^{3}$ The causative reasons for NLDO include congenital (PANDO) and; idiopathic, traumatic, iatrogenic, lithiasis and infection (SANDO). ${ }^{4}$

Endoscopic DCR has gained popularity in recent years, though external DCR remains the gold standard and as the operative procedure of choice. However, success rates of both vary according to surgeon skills, demographics of the patients, and post-operative compliance, hence success rates ranging between $63 \%$ and $93 \%$ in various studies have been reported. ${ }^{5,6}$

Using endoscopic DCR technique in this study, we tried to re-evaluate results for solely endoscopic DCR.

Adding further, results of using silicon intubation along with endoscopic DCR have been inconclusive according to the results of two widely conducted meta-analysis. ${ }^{7}$ Different school of thoughts have either endorsed or negated the use of silicon tubes, with some claiming that it hampers the fibrous closure in the postoperative period, while some claim that their use predisposes to infection, increased tissue granulation and adhesions..$^{8-11}$ Hence, the aim of this study was also to re-evaluate whether patency of the nasolacrimal passage is maintained without the use of tubes, hence evaluating it for a cost- 
benefit analysis in a low socio-economic setup such as that of Pakistan.

\section{MATERIAL \& METHODS}

This prospective, longitudinal, interventional case series was conducted over 13 months, from October 2018 to November 2019. The total number of patients enrolled for the endoscopic procedure was 52 during the given time frame. Before the initiation of the study, a permission grant was obtained from the Institutional Research Forum of Rawalpindi Medical University.

Patients who presented with the complaint of epiphora to the Department of Ear, Nose, and Throat were evaluated for their symptoms by an ophthalmologist and an ENT specialist initially. Cases with primary or secondary nasolacrimal duct obstruction were considered. Clinical examination and laboratory investigations were done to identify associated factors, diseases and to rule out any contraindications for surgical procedures. If the patient was found to be having an active infection, antibiotics (Amoxicillin with Clavulanic Acid) were prescribed along with close follow-up. Besides the complete examination of ear, nose, and throat, the patients had a complete examination of eyes by a specialist for ectropion, lid laxity, lacrimal puncta abnormalities, tumors, etc. Syringing and probing were the key diagnostic investigations for identifying a case of NLD obstruction. The exclusion criteria included children less than fifteen years, patients with canalicular or punctual obstruction, ectropion, lower lid laxity, lacrimal sac tumor, patients previously operated for NLD obstruction, or cases with co-morbidities deeming them as medically unfit for surgical procedures.

The procedure of Endoscopic DCR was performed under general anesthesia, with an injection of Lignocaine with Adrenaline in the lateral wall of the nose. 30 degrees Endoscope was used to visualize the nasal cavity. Initially, an incision was made in the lateral wall of the nose, the flap was raised, the bony crest was removed using Rongers, the lacrimal sac was exposed, a vertical incision was given, and was opened in its full length. Finally, the nasal mucosa was approximated with that of the lacrimal sac mucosa. Silastic tubes were not placed during the procedure.

Post-operative instructions to the patients included the usage of painkillers (Diclofenac Sodium), antibiotics (Amoxicillin with Clauvilinic acid), decongestant topical drops (Xylometazoline), regular nasal douches, proper hygiene maintenance, regular follow-up and preventive measures to ensure early healing. Patency of the ducts and presence of epiphora was checked by syringing and 0 -degree endoscopic examination at $3^{\text {rd }}, 4^{\text {th, }}$ and $6^{\text {th }}$ month. Outcomes were classified as patent and non-patent. Follow-up compliance was ensured by regular reminders given to the cases through mobile calls, ensuring efficient and fast follow-up appointments, and effectively addressing the patient's complaints.

\section{RESULTS}

The total number of participants that were included in the study was 52 in number, with each participating patient having a pathology in a single eye, hence a total of 52 eyes were involved. The age distribution of the participants is given in Table-l.

\begin{tabular}{|l|c|}
\hline \multicolumn{1}{|c|}{ Parameter } & Age in Years \\
\hline Mean & 36.6 \\
\hline Standard Deviation & 13.3 \\
\hline Maximum Value & 70 \\
\hline Minimum Value & 13 \\
\hline \multicolumn{2}{|c|}{ Table-l. Age distribution of the study participants. } \\
\hline
\end{tabular}

Of the 52 participants, 18 (34.6\%) were males while $34(65.4 \%)$ were females. There was no predominance of involvement of a particular side, as 26 (50\%) patients, each presented in each of the categories of right and left-sided eye. The patients presenting to the department had a history of infection, which varied in frequency, as shown in Table-Il.

During the per-operative clinical examination of the discharge, 26 (50\%) patients presented with mucopurulent discharge while 26 (50\%) presented with purulent discharge. The type of 
discharge varied with the number of infections the patient had, $(P=<0.001)$, as shown in Table-III.

\begin{tabular}{|c|c|c|c|c|}
\hline \multicolumn{5}{|c|}{ Eye Infection in Past 1 Year } \\
\hline & \multicolumn{2}{|c|}{ Frequency } & \multicolumn{2}{|c|}{ Percent } \\
\hline no infection & \multicolumn{2}{|r|}{12} & \multicolumn{2}{|c|}{$23.1 \%$} \\
\hline$<3$ & \multicolumn{2}{|r|}{23} & \multicolumn{2}{|r|}{$44.2 \%$} \\
\hline 3-6 episodes & \multicolumn{2}{|r|}{17} & \multicolumn{2}{|c|}{$32.7 \%$} \\
\hline \multicolumn{5}{|c|}{ Table-II. Eye Infection in Past 1 year. } \\
\hline \multicolumn{5}{|c|}{ Eye Infection In Past 1 Year } \\
\hline \multicolumn{2}{|c|}{ Discharge } & $\begin{array}{c}\text { No } \\
\text { Infection }\end{array}$ & $<3$ & $\begin{array}{c}\text { 3-6 } \\
\text { Episodes }\end{array}$ \\
\hline \multicolumn{2}{|c|}{ Mucopurulent Discharge } & 12 & 13 & 1 \\
\hline \multicolumn{2}{|c|}{ Purulent Discharge } & 0 & 10 & 16 \\
\hline $\begin{array}{r}\text { Table-III. } \\
\text { disc }\end{array}$ & abu & $\begin{array}{l}\text { ation betwe } \\
\text { listory of in }\end{array}$ & $\mathrm{n}$ the & $\begin{array}{l}\text { type of } \\
\text { s. }\end{array}$ \\
\hline
\end{tabular}

The patients were also evaluated for postoperative progress in terms of the presence of epiphora and patency as shown in Figure I and Figure II respectively. The results show that 50 (96.2\%) patients had a patent nasolacrimal system and negative epiphora from 12 weeks onwards, while only 2 (3.8\%) had blocked nasolacrimal ducts and positive epiphora which remained as they were by the end of 24 weeks of follow-up showing no improvement.

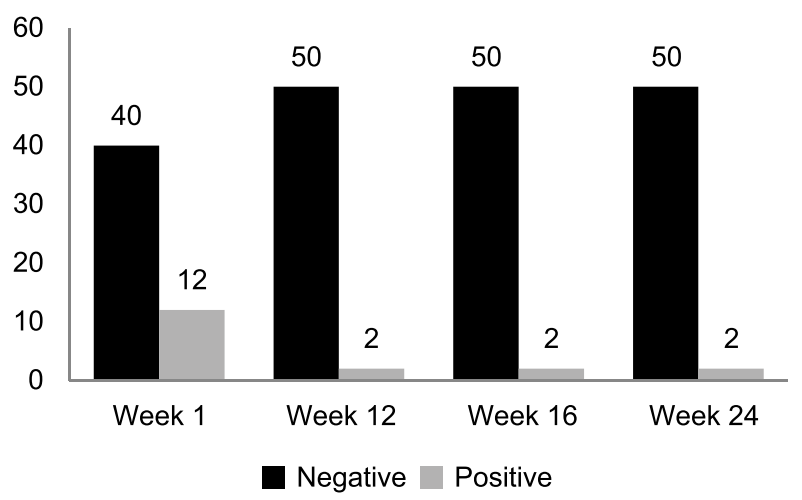

Figure-1. Presence of epiphora in the postoperative follow-up period.

\section{DISCUSSION}

Endoscopic DCR has now been regarded as the gold standard procedure in the treatment of NLD obstruction and has surpassed External DCR due to many of its advantages such as no scar marks, decreased bleeding, reduced operative time, preservation of medial canthal ligament, reduced post-operative healing time and shortened hospital stay. ${ }^{12-15}$

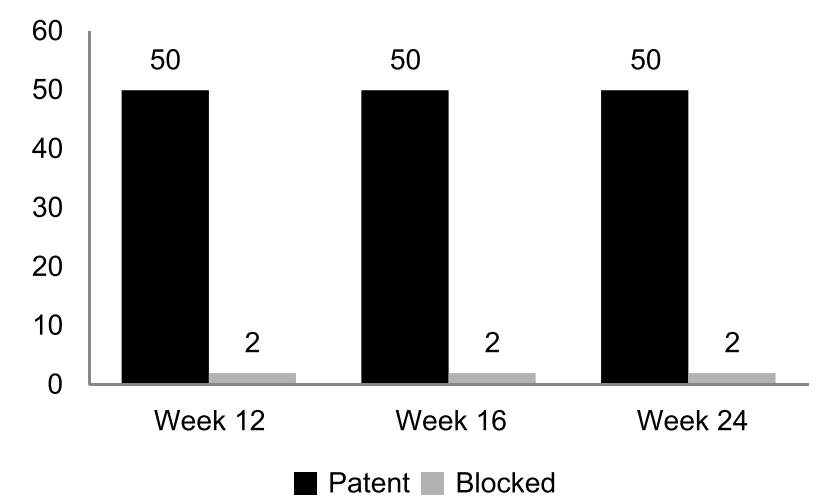

Figure-2. Patency of NLD in the postoperative follow-up period.

As a result, external DCR rules out as a nonpreferable surgical procedure considering the wide advantages endoscopic DCR has comparatively.

However, the question of whether the usage of silicon tubes leads to long term benefit remains unrequited. According to a meta-analysis done by Kang MG et al, endoscopic DCR with intubation had an overall success rate of $92.9 \%$ while without intubation it was $91.2 \%{ }^{7}$, while the success rates of endoscopic DCR without intubation in our study were $96.2 \%$, which are higher.

In Pakistan, a study followed the same surgical methodology as ours and reported success rates of $92 \%$, which were relatively less than ours. ${ }^{16}$ However, a cohort study conducted Gujranwala in 2013 reports a comparison of $80 \%$ success rate without intubation and $92.5 \%$ with intubation. ${ }^{17}$ Similarly, research conducted at Khyber Institute of Ophthalmic Medical Sciences in 2005 reported 95\% success rates without intubation and $97.5 \%$ success rates with intubation, however, results were statistically not significant. ${ }^{18}$ The current study, Endoscopic DCR without intubation, yielded results of $96.5 \%$ which are close to the results achieved in the above studies where intubation was performed.

A study conducted in Turkey, however, yielded opposite results, with surgical success without intubation in $94.7 \%$ of candidates, but with 
intubation $84.2 \% .^{10}$ Similar results were reported by another study where procedures without intubation have greater post-operative success. ${ }^{19}$ Hence, concluding to the notion that results vary across different studies. The question that remains unanswered is whether intubation is necessary or not?

\section{CONCLUSION}

With success rates reaching almost the same as those with intubation, our set-up would well sustain on conducting endoscopic DCR without intubation considering a variety of factors at hand. Firstly, intubation is relatively costly and puts a strain on finances. Adding further, the procedure gets technical, per-operative time increases, there is a chance of extrusion and displacement, patients complain of infection, irritation and uncomfortable sensation, and lastly, a strict followup is required. Considering all these factors, and the close proximity of our results to studies using intubation, we recommend Endoscopic DCR without intubation in an economically burdened setup.

Copyright@ 24 Dec, 2020.

\section{REFERENCES}

1. Saha R, Sinha A, Phukan JP: Endoscopic versus external approach dacryocystorhinostomy: A comparative analysis. Niger Med J. 2013; 54(3):165. 10.4103/0300-1652.114580.

2. Al-Marashdi IMJ: Endoscopic versus external approach dacryocystorhinostomy: Iraqi study. JUBPAS. 2018; 26(9):271-81.

3. Sweeney AR, Davis GE, Chang SH, Amadi AJ: Outcomes of endoscopic dacryocystorhinostomy in secondary acquired nasolacrimal duct obstruction: A case-control study. Ophthalmic Plast Reconstr Surg. 2018; 34(1):20-5.10.1097//OP.0000000000000841.

4. Nakayama T, Watanabe A, Rajak S, Yamanaka Y, Sotozono C: Congenital nasolacrimal duct obstruction continues trend for spontaneous resolution beyond first year of life. Br J Ophthalmol. 2020; 104:1161 1163. dx.doi.org/10.1136/bjophthalmol-2019-314980.

5. Tarbet KJ, Custer PL: External dacryocystorhinostomy: Surgical success, patient satisfaction, and economic cost. Ophthalmology. 1995; 102:1065-70. 10.1016/ s0161-6420(95)30910-4
6. Durvasula VS, Gatland DJ: Endoscopic dacrocystorhinostomy: long-term results and the evolution of surgical technique. J Laryngol Otol. 2004; 118(8):628-32. 10.1258/0022215041917835.

7. Kang MG, Shim WS, Shin DK, Kim JY, Lee JE, Jung $\mathrm{HJ}$ : A systematic review of the benefit of silicone intubation in endoscopic dacryocystorhinostomy. Clin Exp Otorhinolaryngol. 2018; 11(2):81-88. 10.21053/ ceo.2018.00031.

8. Tsirbas A, Wormald PJ: Endonasal dacryocystorhinostomy with mucosal flaps. Am J Ophthalmol. 2003; 135(1):76-83. 10.1016/s00029394(02)01830-5.

9. Caversaccio $M$, Häusler $R$ : Insertion of double bicanalicular silicone tubes after endonasal dacryocystorhinostomy in lacrimal canalicular stenosis: A 10-year experience. ORL. 2006; 68(5):2669. 10.1159/000093096.

10. Unlu HH, Gunhan K, Baser EF, Songu M: Long-term results in endoscopic dacryocystorhinostomy: Is intubation really required?. Otolaryngol Head Neck Surg. 2009; 140(4):589-95. 10.1016/j. otohns.2008.12.056.

11. Al-Qahtani AS: Primary endoscopic dacryocystorhinostomy with or without silicone tubing: A prospective randomized study. Am J Rhinol Allergy. 2012; 26(4):332-4. 10.2500/ajra.2012.26.3789

12. Shun-Shin GA, Thurairajan G: External dacryocystorhinostomy -an end of an era?. $\mathrm{Br} J$ Ophthalmol. 1997; 81(9):716-7. 10.1136/bjo.81.9.716.

13. Watters GW, Whittet HB, Shun-Shin GA, Milford CA: Endoscopic transnasal dacryocystorhinostomylong-term results. Minim Invasive Ther Allied Technol. 1996; 5:505-10. 10.3109/13645709609152692

14. Karim R, Ghabrial R, Lynch TF, Tang B: A comparison of external and endoscopic endonasal dacryocystorhinostomy for acquired nasolacrimal duct obstruction. Clin Ophthalmol. 2011; 5:979-89. 10.2147/OPTH.S19455.

15. Ahmad R, Rafique A, Latif S: Endoscopic Dacryocystorhinostomy: Experience at Sheikh Zayed Hospital, Lahore. Pak J Otolaryngol. 2013; 29:74-6.

16. Ayoob M, Mahida K, Ul-ain Q, Dawood Z: Outcome and complications of endoscopic dacryocystorhinostomy without stenting. Pak J Med Sci. 2013; 29(5):1236-39. 10.12669/pjms.295.3393. 
17. Afzal MM, Mehmood AS, Maqbool RE, Malik IQ, Rehman A: To compare the success rate of external dacryocystorhinostomy with and without silicone intubation in patients of nasolacrimal duct obstruction. Pak J Med Health Sci. 2014; 8:53-5.

18. Zaman M, Babar TF, Abdullah A: Prospective randomized comparison of dacryocystorhinostomy (DCR) with and without intubation. Pak J Med Res. 2005; 44(2):75-8.
19. Smirnov G, Tuomilehto $H$, Terasvirta M, Nuutinen J, Seppa J: Silicone tubing is not necessary after primary endoscopic dacryocystorhinostomy: A prospective randomized study. Am J Rhinol. 2008; 22(2):214-7. 10.2500/ajr.2008.22.3132.

\begin{tabular}{|c|l|l|l|}
\hline \multicolumn{3}{|c|}{ AUTHORSHIP AND CONTRIBUTION DECLARATION } \\
\hline Sr. \# & \multicolumn{1}{|c|}{ Author(s) Full Name } & Contribution to the paper & Author(s) Signature \\
\hline 1 & Nayyer Ayub & 1st Author & \\
\hline 2 & Ahmed Hasan Ashfaq & 2nd Author & \\
\hline 3 & Haitham Akash & 3rd Author & \\
\hline 5 & M. Sheharyar Khan & Mth Author \\
\hline 6 & Malik Jawad Faisal & 5th Author & \\
\hline
\end{tabular}

